\title{
Impact of Vermicompost Fertilizer on Spinach Yield and Nutritional Components
}

ISSN: 2637-7659

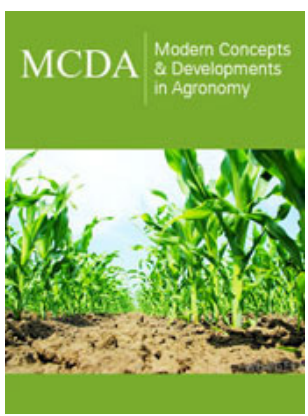

*Corresponding author: S Alan Walters, Department of Plant, Soil, and Agricultural Systems, Southern Illinois University, Carbondale IL, 62901, USA

Submission: 監June 04, 2020

Published: 蹒June 22, 2020

Volume 6 - Issue 4

How to cite this article: April Vigardt, Marlee A Trandel, Ruplal Choudhary, S Alan Walters. Impact of Vermicompost Fertilizer on Spinach Yield and Nutritional Components. Mod Concep Dev Agrono. 6(4). MCDA. 000643. 2020. DOI: 10.31031/MCDA.2020.06.000643

Copyright@ S Alan Walters, This article is distributed under the terms of the Creative Commons Attribution 4.0 International License, which permits unrestricted use and redistribution provided that the original author and source are credited.

\author{
April Vigardt ${ }^{1}$, Marlee A Trandel ${ }^{2}$, Ruplal Choudhary ${ }^{3}$, S Alan Walters ${ }^{3 *}$ \\ ${ }^{1} 1175$ S. Brady Ave, North Carolina Cooperative Extension, Newton NC, 28658, USA \\ ${ }^{2} 600$ Laureate Way, Plants for Human Health Institute, Department of Horticultural, Sciences, \\ North Carolina State University, Kannapolis, NC 28081, USA
}

${ }^{3} 1205$ Lincoln Drive, Department of Plant, Soil, and Agricultural Systems, Southern Illinois University, Carbondale IL, 62901, USA

\begin{abstract}
Alternative fertilization practices, such the use of vermicompost (VC), have shown great potential to improve both the physical and biological attributes of soils and supplement the nutrient status of soils to improve fertility for vegetable crop production. Modification of soils with coffee vermicompost (CVC) has the potential to improve soil organic content, structure, and microbial activity. Generally, organic fertilizers with slow release nutrient capabilities efficiently use nitrogen and reduce nitrate levels in leafy green vegetables and have been shown to increase ascorbic acid (AA) content. A greenhouse study was conducted over two growing seasons (2011 and 2012) to assess the influence of four CVC rates (0, $25 \%, 50 \%$, and $75 \% \mathrm{v} / \mathrm{v}$ of soil $\mathrm{mix}$ ) on Spinacia oleracea growth parameters including fresh leaf weight, leaf area, plant height, leaf number, fresh leaf ascorbic acid (AA) and dry leaf nitrate (DLN). Spinach leaf number and fresh leaf weight increased with CVC rate for both growing seasons and were best described by increasing linear relationships. Surprisingly, spinach AA content remained the same whether DLN content was high or low; and AA and nitrate content were both at highest levels with the $75 \% \mathrm{v} / \mathrm{v}$ CVC treatment in both years. These results indicated that applications of an alternative fertilizer such as CVC can improve spinach yield and that AA content does not always decrease with higher VC application rates, even as nitrate content increases.
\end{abstract}

Keywords: Ascorbic acid; Coffee vermicompost; Leaf nitrate; Organic agriculture

\section{Introduction}

Vermicomposting is the mesophillic processing of organic wastes by epigeic earthworms (Eisenia fetida) into a stabilized product that is high in organic matter, plant available nutrients, beneficial bacteria, plant growth regulators (PGRs), and extracellular enzymes [1-11]. This fertilizer product has the potential to be part of an effective composting system for closed loop agriculture that recycles all nutrients and organic matter materials back into the soil, allowing for more sustainable farming practices. In most agricultural production systems, high amounts of nitrogen $(\mathrm{N})$ and phosphorus $(\mathrm{P})$ fertilizers are relied upon to maximize yields, which has directly resulted in numerous environmental issues [12]. Closing the nutrient loop would prevent many of these issues, especially when materials such as composts or other organic materials with lower amounts of nutrients are applied at times that match plant nutrient requirements. The application of VC has been shown to enhance plant growth, yields and quality through a synergism of physical, chemical and biological properties in the growth medium. The addition of $25 \%$ to $50 \%$ VC in greenhouse medium has been shown to increase plant growth and yield for numerous crops (including greenhouse lettuce, tomatoes, peppers, strawberries, marigolds and petunias), although plant growth and yield decreased when VC application rates exceeded 50\% [4,13-17]. These growth and yield responses have been attributed to the presence of PGRs produced from microbial activity, which enhance plant growth in small amounts, but provide an inhibition response at higher rates [16].

Many organic materials have been effectively used to produce VC, including animal manures [16,18], sewage sludge [15,19], paper pulp [13,14], and coffee grounds [20-22]. The addition of VC produced from these different substrates has similarly improved plant growth and yield among a broad spectrum of plant species and cultivars. The chemical and biological characteristics of $\mathrm{VC}$ are influenced by the substrate, and rate recommendations may need 
to be altered depending on the materials utilized [13-15,17,19]. Although coffee as a substrate to produce VC has been evaluated in several studies [20-22], there is still limited information available regarding the influences on plant growth and yield, particularly for greenhouse crops such as spinach, lettuce and other fast growing salad greens. Moreover, CVC is also high in N (3.2\% to $3.6 \%)$ $[21,22]$, soluble P, Ca and Mg [22], which are oftentimes some of the nutrients most limiting for crop production. In addition to improving plant growth and yield, $\mathrm{VC}$ has been found to increase the ascorbic acid (AA) content of some fruits and vegetables, such as tomatoes [23], strawberries [24], and lettuce [25]. The AA content in fruits and vegetables is influenced by the interaction of multiple environmental factors with plant genetic and plant nutritional components. Environmental factors, such as light quality and duration, play a significant role and are responsible for many of the diurnal and seasonal differences observed regarding AA content [26,27].

Furthermore, the application of high rates of inorganic $\mathrm{N}$ has been known to suppress AA content in many fruits and vegetables, particularly leafy greens such as spinach. Nitrate accumulation and assimilation in leafy greens is affected by $\mathrm{N}$ rate and source, with higher rates resulting in higher leaf content due to luxury accumulation, and organic sources resulting in lower leaf content due to slower $\mathrm{N}$ mineralization [11]. The application of low molecular weight fractions (LMW) of VC has increased nitrate assimilatory enzymes, such as, nitrate reductase (NR) in carrot and maize cells $[6,8,28]$. This is promising for growers that want to reduce nitrate content in leafy greens due to consumer pressures or production regulations, although this could also directly reduce AA content in leafy greens, and other fruits and vegetables. Information regarding the influences of VC (especially CVC) on vegetable growth, yield and resulting nutrient quality is limiting. The aim of this research were to determine the effect of CVC on the nutrient quality (AA and nitrate content) of greenhouse spinach and optimize the application rate of CVC required to obtain the highest AA and lowest nitrate content without compromising spinach yield.

\section{Material and Methods}

\section{Experiment design}

A greenhouse study was conducted over two years from 16 March to 19 April, 2011 and 17 March to 16 April, 2012 at the Southern Illinois University (SIUC) Horticultural Research Center in Carbondale, Illinois. Four CVC treatments were used to determine their influence on growth, yield, AA and nitrate content of 'Bloomsdale Long-Standing' spinach (Spinacia oleracea L.). The experiment was set up as a randomized complete block design with eight replications. The CVC rates evaluated were $0 \%, 25 \%, 50 \%$, and $75 \%(\mathrm{v} / \mathrm{v})$ and were mixed with a medium containing one part sand: one soil : one peat. Clay pots $(4.5 \mathrm{~L})$ were each filled with a specific CVC/1:1:1 soil mix by volume, with proportions based on 3L with 0\% CVC (3 L 1:1:1 mix), 25\% CVC (0.75 L VC/2.25 L 1:1:1), 50\% CVC (1.5 L CVC/1.5 L 1:1:1), and 75\% CVC (2.25 L CVC/0.75 L 1:1:1). The soil used in the 1:1:1 mix was classified as a Belnap silt loam (coarse-silty mixed, mesic aeric fluvaquent) [29] and the CVC was obtained from the SIUC Vermicomposting Center from red worms (Eisenia fetida) that fed on coffee grounds in an indoor system. These coffee grounds were obtained from Starbucks Coffee Company in the SIUC Student center, and then pre-composted for a month with about $5 \mathrm{~cm}$ applied to the worm bed every five to seven days for four months. Beds were initially prepared using $5 \mathrm{~cm}$ of shredded, wet office paper obtained from SIUC faculty and staff offices as a base with about $10 \mathrm{~cm}$ of worms and coffee grounds placed on top.

All compost was screened with a rotating trammel to homogenize the VC and to also separate out the worms. Both AA and nitrate content are known to be influenced by light quality and diurnal rhythms [26]. Thus, in our study, light was supplemented for 12 hours daily to minimize the effect of cloudy weather on AA and nitrate content, and samples were taken during the early afternoon to minimize diurnal effects. The synthesis of AA is light dependent because of its need for glucose produced in photosynthesis as a source of C-skeletons, and for its role as a reducing agent for $\mathrm{H}_{2} \mathrm{O}_{2}$ and reactive oxygen species (ROS) produced during photosynthesis and photoprotection [30]. Reduced AA levels for spinach have been reported under low light conditions [26,27]. Additionally, nitrate content is diurnal with highest accumulations occurring in the morning and under low light conditions due to the light dependent activity of NR [31].

\section{Vermicompost analysis}

An analysis of the CVC sample was obtained each year, whereas the same soil/sand/peat mixture was used each year, so only one sample was analyzed. All samples were sent to Brookside Laboratories, New Knoxville, Ohio for analysis. The vermicompost analysis each year was somewhat similar (Table 1) with a 6.4 to $7.0 \mathrm{pH}, 8.8$ to $12.1 \mathrm{C} / \mathrm{N}$ ratio, about $50 \%$ organic matter content, and $\mathrm{N}$ content ranging from 28.4 to $41.6 \mathrm{~g} / \mathrm{kg}$ dry weight. Other macronutrients were determined to be at sufficient levels for plant growth with most of the base saturation provided by calcium. For the 1:1:1 soil analysis, the pH was 7.1 and organic matter content $1.9 \%$, with $28.5 \mathrm{mg} \mathrm{N} / \mathrm{kg}$ dry weight. Again, the soil mix was determined to have adequate fertility, with most of the base saturation again provided by calcium.

Table 1: Characteristics of coffee vermicompost used in the spinach greenhouse evaluation for 2011 and 2012.

\begin{tabular}{|c|c|c|c|c|c|c|c|c|c|}
\hline Year & $\mathbf{p H}$ & $\mathbf{C} / \mathbf{N}$ ratio & OM content $^{\mathbf{z}}$ & Nitrogen $^{\mathbf{x}}$ & Phosphorus $^{\mathbf{x}}$ & Potassium $^{\mathbf{x}}$ & Calcium $^{\mathbf{x}}$ & Magnesium $^{\mathbf{x}}$ & Sulfur $^{\mathbf{x}}$ \\
\hline 2011 & 6.4 & 8.8 & 49.1 & 28.4 & 3.5 & 8.2 & 101.4 & 9 & 3.2 \\
\hline 2012 & 7 & 12.1 & 55.3 & 41.6 & 2.8 & 8.8 & 72.4 & 2.7 & 2.1 \\
\hline
\end{tabular}

${ }^{z} \mathrm{OM}$ is organic matter and is presented as percent dry weight of coffee vermicompost.

${ }^{\mathrm{x}}$ Macronutrients are presented as $\mathrm{g} / \mathrm{kg}$ dry weight of coffee vermicompost. 


\section{Spinach growth and data collection}

At planting, six spinach seeds were placed into each pot and covered with $0.6 \mathrm{~cm}$ of soil and placed under 12 hours of supplemental lighting (P.L Light Systems 400W HPS, Hortilux Shreider Group, Canada). At the 2 to 3 leaf stage, spinach seedlings were thinned to three in each pot. The pots were watered daily as needed and the greenhouse temperature averaged $14{ }^{\circ} \mathrm{C}$ (low) to a $28{ }^{\circ} \mathrm{C}$ (high). Data were taken at harvest about 30 days after planting each year on plant height $(\mathrm{cm})$, number of leaves, leaf area $\left(\mathrm{cm}^{2}\right)$ and fresh leaf weights (g). Leaf area was determined using a portable leaf area meter (Li-Cor Portable Area Meter L1-3000, Lambda Instruments Corporation; Lincoln, Nebraska, USA). For AA analysis, newly matured leaves were harvested from the center of each plant and placed in a cooler at $5{ }^{\circ} \mathrm{C}$. Leaves were ground in a metaphosphoric acid solution with a mortar and pestle with the resulting solution titrated with 2, 6 dichloroindophenol within 24 hours [32]. The remaining leaves were washed in deionized water, oven dried at $60^{\circ} \mathrm{C}$ for 60 hours and sent to Brookside Laboratories for nitrate analysis. Samples there were then shaken with $2 \%$ acetic acid and analyzed on a Lachat Quick Chem 8000 auto analyzer (Hach; Loveland, Colorado, USA).

\section{Data analysis}

Data were subjected to analysis of variance procedures using the general linear models procedure of SAS (version 9.4; SAS Institute, Cary, NC). The analysis indicated that growing seasons interacted with vermicompost rates $(\mathrm{P} \leq 0.05)$, therefore data are shown by year. For the assessment of data normality, the Shapiro-Wilkes test was utilized and results indicated that the data were normally distributed. Linear regression analyses were used to ascertain the relationship between vermicompost rate with leaf growth parameters, and AA and nitrate content. Correlation analyses were also used to determine the association of spinach fresh leaf number and weight with ascorbic acid and nitrate content. Lastly, paired t-tests were also used to access if differences existed among CVC rates for certain spinach variables.

\section{Result}

\section{Spinach plant growth characters}

Spinach leaf numbers, fresh leaf weight and leaf area were all affected by CVC rate. Spinach leaf number and fresh leaf weight increased with CVC rate. The number of leaves that developed on each spinach plant followed a linear increase with CVC rate for both years (Figure 1). Compared to no CVC (control), numbers of spinach leaves per plant increased $12 \%, 24 \%$, and $49 \%$, respectively for the $25 \%, 50 \%$, and $75 \%$ CVC rates in 2011. Similarly for 2012, numbers of spinach leaves developing on each plant increased 34\%, 90\%, and $98 \%$ for the $25 \%, 50 \%$, and $75 \%$ CVC rates, respectively. Similar to spinach leaf number, fresh leaf weights in both growing seasons followed a linear response curve with CVC rates (Figure 2). For 2011, fresh leaf weights per plant increased 38\%, 62\%, and $115 \%$, respectively for the $25 \%, 50 \%$, and $75 \%$ CVC rates. In comparison, fresh leaf weights per plant increased 63\%, 237\%, and $280 \%$, respectively for the $25 \%, 50 \%$, and $75 \%$ CVC rates in 2012 .
For both years, paired t-tests indicated differences $(\mathrm{P}<0.05)$ among all CVC rates for the percent increase in spinach fresh leaf number and weight. Additionally, spinach leaf area was collected only for 2011 and increased in a quadratic manner from $73.0 \mathrm{~cm} 3$ with no CVC to $122.6 \mathrm{~cm} 3$ for the $75 \%$ CVC rate (Figure 3).

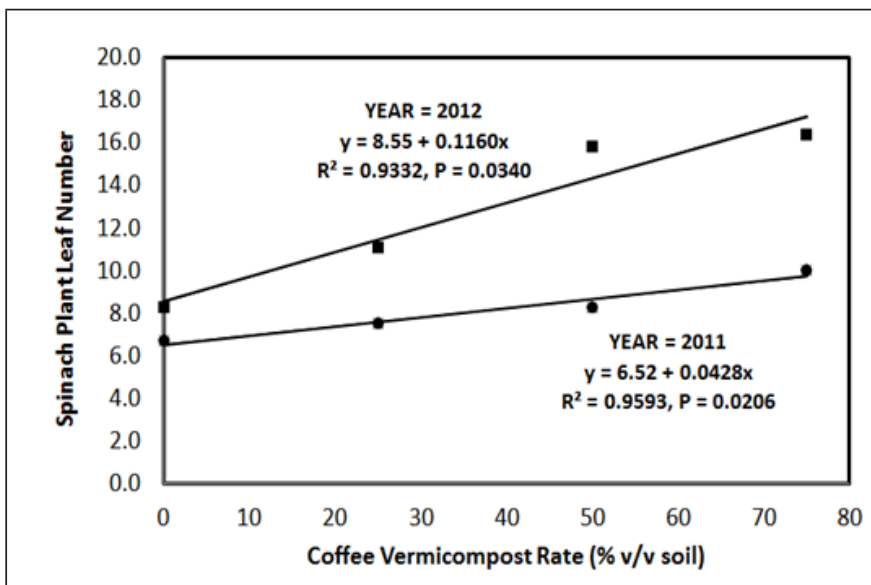

Figure 1: Influence of coffee vermicompost rate on development of spinach leaves in 2011 and 2012.

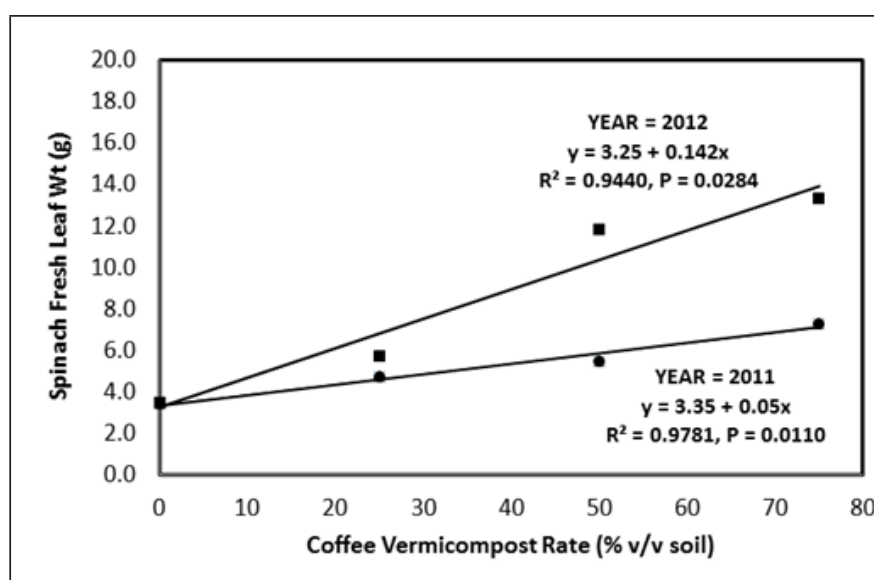

Figure 2: The influence of coffee vermicompost rate on development of spinach fresh leaf weight (g) in 2011 and 2012.

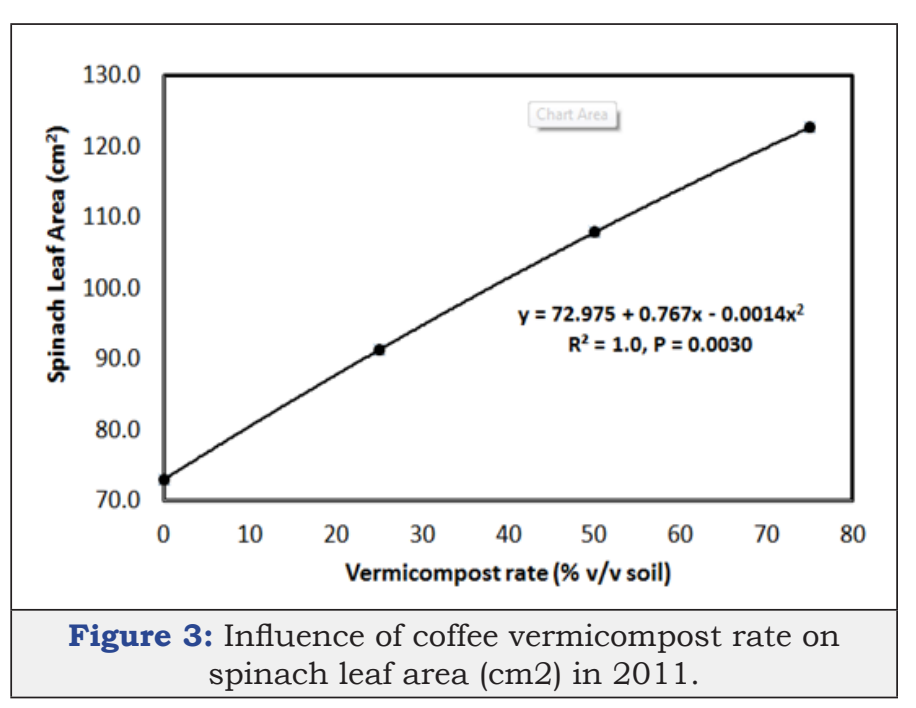




\section{Coffee vermicompost and spinach leaf ascorbic acid composition}

Spinach leaf AA content was also influenced by CVC rate. In both years, spinach leaf AA content increased in a linear manner with CVC application rate from 0 to $75 \%$ (Figure 4). In 2011, spinach AA content was highest at $75 \%$ CVC $(65.2 \mathrm{mg} / 100 \mathrm{~g}$ leaf dry weight $)$ compared to all other treatments, with a low of $43.4 \mathrm{mg} / 100 \mathrm{~g}$ with no CVC. In 2012, AA content was much lower and less variable, ranging from a low of $48.9 \mathrm{mg} / 100 \mathrm{~g}$ with no CVC to a high of $54.8 \mathrm{mg} / 100 \mathrm{~g}$ at $75 \%$ CVC. Moreover, the slope coefficient of the linear model for leaf AA content in 2011 was almost four times that observed for the 2012 linear model, indicating a greater effect of each CVC rate during 2011.

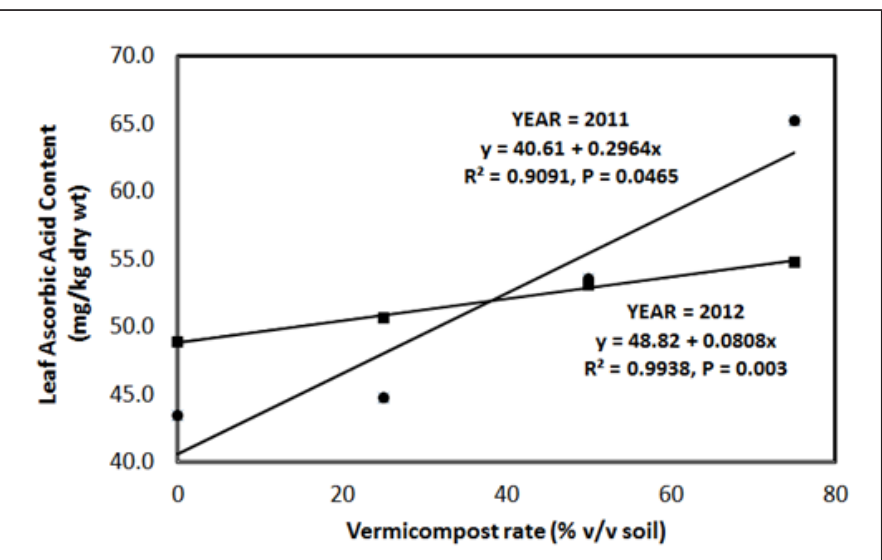

Figure 4: Influence of coffee vermicompost rate on ascorbic acid content in spinach leaves during 2011 and 2012 .

\section{Coffee vermicompost and spinach leaf nitrate} composition

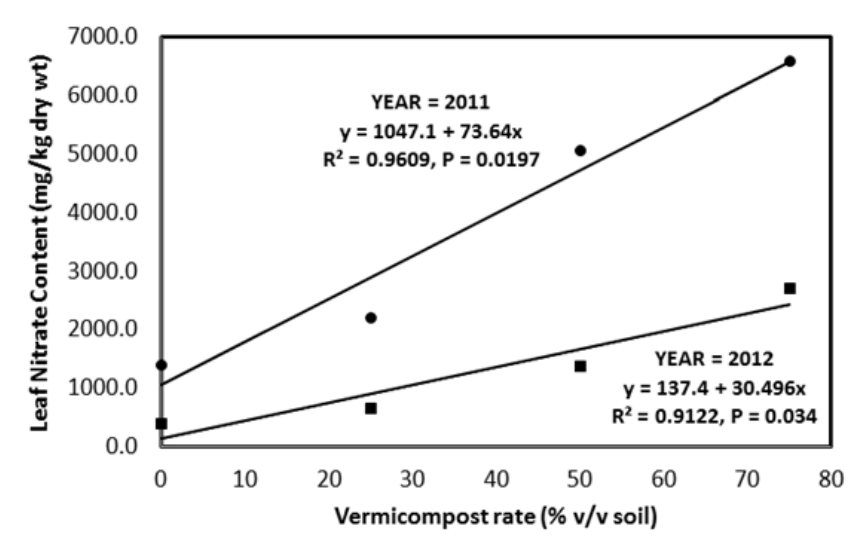

Figure 5: Influence of coffee vermicompost rate on leaf nitrate content in spinach leaves during 2011 and 2012.

The CVC rate utilized also influenced the resulting spinach leaf nitrate content. For both years, spinach leaf nitrate content increased in a linear manner with percentage of CVC in the medium (Figure 5). For 2011, spinach leaf nitrate content increased almost 5 -fold from the $0 \%(1,397 \mathrm{mg} / 100 \mathrm{~g})$ to $75 \% \mathrm{CVC}$ rate $(6,587 \mathrm{mg} / 100 \mathrm{~g})$; and in comparison, spinach leaf nitrate content increased almost 7 -fold from a low of $395 \mathrm{mg} / 100 \mathrm{~g}$ with no CVC to $2,695 \mathrm{mg} / 100 \mathrm{~g}$ at the $75 \%$ CVC rate for 2012. Similar to leaf AA content, the slope coefficient of the linear model for spinach leaf nitrate content in 2011 was more than twice that observed for the 2012 linear model, indicating a greater effect of each CVC rate during 2011.

\section{Spinach leaf ascorbic acid and nitrate associations}

The two spinach leaf nutritional components evaluated, AA and nitrate, were closely associated. In both years, AA leaf content was positively correlated with nitrate content $(r=0.97$, $\mathrm{P}=0.0297$ for 2011 ; $\mathrm{r}=0.95$ and $\mathrm{P}=0.0491$ for 2012 ). These results further indicated that AA content in spinach leaves increased with increasing nitrate levels.

\section{Discussion}

\section{Spinach leaf yield and CVC}

This study indicated that spinach leaf growth characters, as well as the nutritional components, $\mathrm{AA}$ and nitrate, increased with CVC additions. Both spinach leaf number and fresh leaf weight linearly increased with CVC rate, whereas leaf area increased in a quadratic manner (Figures 1-3). The highest CVC rate provided the greatest amount of plant growth. However, other studies have indicated additions of vermicompost to a growth medium tend to provide the highest amounts of plant growth around 50\%, with a decline then observed at higher percentages $[4,16]$. Rates of VC higher than $50 \%$ are thought to negatively affect the physical structure of the growth medium by increasing water retention at the expense of root aeration. Since spinach in this study was grown in a medium containing $1 / 3$ sand, this may have prevented soil water-logging from occurring. This issue of high VC rate inhibition on plant growth can also be partially explained by plant growth hormones (PGRs) that adsorb onto the VC humic fraction, as VC is known to improve plant growth at low concentrations and provide inhibition at higher concentrations $[14,33]$.

This suggests the CVC used in our study may have had lower PGR levels compared to that used in some other published studies. Spinach leaf growth in our study was also greater in 2012 compared to 2011 (Figure 2). This increase observed in 2012 may have been related to the fact that the CVC used was harvested from an active worm bed with a moisture content of $71 \%$ in 2012 , compared to 2011, in which the bed was less active and had a lower moisture content of 43\%. The higher microbial activity during 2012 could have also increased PGRs to levels that promoted more vegetative growth. Microbial activity and PGRs are known to enhance nitrate assimilation [28,31], which may have increased accumulation in spinach plants, without having an overall detrimental impact on leaf growth. Additionally, humic acids may also have played a role, since the application of humic acids above $500 \mathrm{mg} / \mathrm{kg}$ to a peat based commercial greenhouse medium has been shown to inhibit both cucumber and tomato plant growth [4]. However, spinach is grown for its foliage with no fruit sinks to draw assimilates (unlike cucumber and tomato that have fruit), which probably played some role in having high amounts of leaf growth at high CVC rates. 


\section{AA and nitrate in spinach leaves}

Leafy vegetables, such as spinach, tend to accumulate nitrates in their petioles when nitrate reserves are high for possible later reduction. This reduction of nitrate reserves can be rapid, and nitrate stores can be depleted within 48 hours [31]. Therefore, slow release fertilizers or an intermittent nutrient supply has been suggested to reduce nitrate content in fruits and vegetables $[26,34]$. In our study, AA content did not decrease as nitrate content increased in spinach leaf tissue (Figures 4\&5). Although spinach fertilized with inorganic sources provide $\mathrm{N}$ that is immediately available for plant uptake, fertilization with an organic source (such as $\mathrm{CVC}$ ) provides $\mathrm{N}$ that will be released more slowly. Thus, nitrate uptake would be reduced and taken up at a slower rate, decreasing luxury accumulation. Another possible factor for reduced nitrate composition in spinach leaves may result from the stimulation of $\mathrm{NR}$, which would further reduce the assimilation of nitrate into plant tissues $[8,9,35]$. Also, the differences in the range of nitrate composition observed between 2011 and 2012 can possibly be related to the difference in the CVC age. Due to the difference in CVC harvest times, more mineralized total N may have occurred in 2011 than 2012 allowing for more plant available N; whereas, microbial activity may have been more pronounced in 2012, possibly stimulating a hormonal trigger of $\mathrm{N}$ metabolism and assimilation.

This study indicated that spinach AA content remains the same whether nitrate content is high or low. Surprisingly, AA and nitrate content were both at high levels with the $75 \% \mathrm{v} / \mathrm{v}$ CVC treatment in both years (Figures $4 \& 5$ ). It appears that CVC may be an important medium addition allowing for the preservation of AA during times of high nitrate accumulation in spinach. In most cases, the content of AA in fruits and vegetables has been shown to have an inverse relationship with nitrogen fertilization. As $\mathrm{N}$ fertilization rates increase, AA content tends to decrease in many fruits and vegetables [26]. One explanation for this inverse relationship between AA and nitrate content in spinach, concerns the use of AA as a precursor for oxalate [30], since it can be synthesized in the cytosol and stored in the vacuole to maintain cation-anion balance and intracellular $\mathrm{pH}$ during nitrate assimilation [31]. Spinach is known to be high in oxalates, especially with high rates of $\mathrm{N}$ fertilization [36,37]. A change in $\mathrm{N}$ metabolism may affect oxalate and AA content in spinach. Additionally, AA and nitrate content are known to be influenced by other factors, such as light quality and diurnal rhythms [26].

In our study, light was supplemented for 12 hours daily to minimize the effect of cloudy weather on AA and nitrate content, and samples were taken during the early afternoon to minimize diurnal effects. The synthesis of AA is light dependent because of its need for glucose produced in photosynthesis as a source of C-skeletons, and the role of AA as a reducing agent for $\mathrm{H} 2 \mathrm{O} 2$ and reactive oxygen species produced during photosynthesis and photoprotection [30]. Reduced AA levels for spinach have been reported under low light conditions [26,27]. Nitrate content is diurnal with highest accumulations occurring in the morning and under low light conditions due to the light dependent activity of NR [31]. Spinach AA content has been reported within the range of 15 to $54 \mathrm{mg} / 100 \mathrm{~g}[26,27]$, and found to increase in winter under high light, with an optimum temperature range of 12 to $15^{\circ} \mathrm{C}$ [26]. The range of AA for this study was 43.4 to $65.2 \mathrm{mg} / \mathrm{kg}$ in 2011, and 47.6 to $53.9 \mathrm{mg} / \mathrm{kg}$ in 2012 . The average high/low greenhouse temperatures for the duration of this study were 16 to $29^{\circ} \mathrm{C}$, which was higher than the optimum and potentially decreased AA content. The variability of nitrate content found in this study reflects that reported in previous studies [27], but since we controlled light quality and diurnal seasonal effects, this variation can most likely be attributed to other factors.

\section{CVC and $\mathrm{N}$ availability}

Some immobilization of inorganic $\mathrm{N}$ through microbial activity probably occurred to some extent in this study. Although a $\mathrm{C} / \mathrm{N}$ ratio of about 9 to 12 was determined for CVC used in this study (Table 1), $\mathrm{N}$ mineralization in the organic material was potentially slower due to a higher amount of phenolic $\mathrm{C}$ present. The chemical composition of compost substrates with $\mathrm{C} / \mathrm{N}$ ratios around 12 could have significant effects on $\mathrm{N}$ mineralization by influencing the type and abundance of extracellular enzymes (such as urease and protease) and microbial activity [10]. Moreover, nitrification is the primary form of $\mathrm{N}$ mineralization in $\mathrm{VC}$ with nitrate accounting for $99 \%$ of the inorganic $\mathrm{N}$ after a 16 week soil incubation period, and the rate of $\mathrm{N}$ mineralization is known to increase in a linear manner with about half of total inorganic $\mathrm{N}$ available at 4 weeks [10]. Fungal species tend to dominate VC, which increases nitrate mineralization compared to ammonium mineralization [3]. In our study, the $\mathrm{N}$ mineralization rate may have also stabilized in 2011 due to decreased microbial activity as VC was not harvested from a vigorous and active worm bed; whereas for 2012, these biological processes may have been more functional in an more active worm bed. Additionally, the uptake of organic nitrogen in the form of amino acids possibly allowed for increased growth without nitrate accumulation [31,38].

\section{CVC and nutrient availability}

The addition of VC to soil or soil-less growing media has been shown to positively increase growth of many fruits, vegetables and ornamental plants, which has been attributed to an increase in plant available nutrients, improved soil/media physical structure, increased microbial activity, humic fractions and the presence of plant hormones [4,39]. Plant available P, K, Ca and Mg was higher in $\mathrm{VC}$ of diverse parent materials $[2,7,11,22]$, and $\mathrm{N}$ mineralization rates were higher in VC processed municipal waste compared to thermogenic composting $[10,11]$. Soil and compost analysis indicated that all nutrients were within the optimum range needed for spinach growth, with phosphorus, potassium and sulfate higher than the optimum. However, the estimation of adequate nitrogen release based on organic matter content and microbial activity has been difficult. Yield was higher in 2012 than 2011, although a nitrate deficiency was revealed through spinach leaf tissue analysis. This suggests that the positive effect of VC on spinach growth cannot entirely be attributed to an increase in mineral nutrition. The improvement of soil physical structure by the addition of VC should also be considered, since when VC is added to soil, there 
is an increase in water stable aggregates, total porosity and water holding capacity [16]. Plant nutrient uptake is enhanced when VC is present. This may be partially explained by the increased activity of $\mathrm{H}+$ ATPase and the subsequent increase of plasma membrane permeability found in studies using humic substances extracted from VC. Humic acid extracted from VC has been shown to stimulate ATPase activity, root elongation and lateral root formation of maize roots [6].

The release of protons from ATPase would contribute to the acidification of the root rhizosphere and the formation of an electrochemical gradient across the plasma membrane, which positively influences plant nutrient uptake [40,41]. Low molecular weight (LMW) humic fractions (<3500MW) extracted from VC also stimulated an increase in $\mathrm{H}+$ ATPase activity, which related to a $70 \%$ and $50 \%$ increase of nitrate uptake in maize roots and nitrate accumulation in leaves, respectively [9]. Moreover, humic fractions $(<9000 \mathrm{MW})$ and unfractionated humic substances extracted from grassland soil stimulated nitrate uptake of barley seedlings [28]. Additionally, an important PGR, indole acetic acid (IAA), extracted from diverse soils has also been found in humic acid [6] and in LMW humic substances $(<3500 \mathrm{MW})$ [8]. Other PGRs, such as cytokinins and auxins, were found in the intestines of large earthworm populations, with positive correlations $(\mathrm{r}=0.97, \mathrm{P}<0.05)$ detected between earthworm populations and the levels of auxins and cytokinins in ten different soils [42]. The PGRs present in VC are thought to result from microbial activity in VC and earthworm gut, although the endogenous production of PGRs by earthworms has not yet been conclusively determined.

The positive effect of CVC on spinach growth observed is most likely not due to any one factor alone, but rather a synergism between improved soil physical, biological and chemical properties. Due to the older age of the CVC in 2011, improved spinach growth was most likely due to improved physical properties of the soil and increased mineral nutrition, while in 2012, the growth increase in spinach was probably more related to an improvement in the overall biological system.

\section{Conclusion}

This study demonstrated that spinach leaf growth characters and the nutritional components, AA and nitrate, increased with CVC rate. The highest CVC rate at $75 \% \mathrm{v} / \mathrm{v}$ provided the greatest amount of plant growth, and highest leaf AA and nitrate levels. Spinach AA content remained the same whether nitrate content was high or low, and surprisingly, AA and nitrate content were both at highest levels in the 75\% CVC treatment during both years. It appears that CVC may be an important medium addition with properties that stimulate nitrate uptake and assimilation, allowing for the preservation of AA composition during high rates of nitrate accumulation in spinach. These results indicated that applications of an alternative fertilizer such as CVC can improve the yield of spinach, and that under controlled spring greenhouse growing conditions, the AA content does not decrease with higher CVC application rates, even as nitrate content increases.

\section{References}

1. Aira M, Monroy F, Domínguez J (2007) Microbial biomass governs enzyme activity decay during aging of worm-worked substrates through vermicomposting. J Environ Qual 36(2): 448-452.

2. Albiach R, Canet R, Pomares F, Ingelmo F (2000) Microbial biomass content and enzymatic activities after the application of organic amendments to a horticultural soil. Bioresource Technol 75(1): 43-48.

3. Anastasi A, Varese GC, Voyron S, Scannerini S, Marchisio VF (2004) Characterization of fungal biodiversity in compost and vermicompost. Compost Sci and Utilization 12(2): 185-191.

4. Atiyeh RM, Lee S, Edwards CA, Arancon NQ, Metzger JD (2002) The influence of humic acids derived from earthworm- processed organic wastes on plant growth. Bioresource Technol 84(1): 7-14.

5. Bernitez E, Sainz H, Nogales R (2004) Hydrolytic enzyme activities of extracted humic substances during the vermicomposting of a lignocellulosic olive waste. Bioresource Technol 96(7): 785-790.

6. Canellas LP, Olivares FL, Okorokova Facanha AL, Facanha AR (2002) Humic acids isolated from earthworm compost enhance root elongation, lateral root emergence, and plasma membrane $\mathrm{H}^{+}$- ATPase activity in maize roots. Plant Physiol 130(4): 1951-1957.

7. Edwards CA, Bohlen PJ (1995) Biology and ecology of earthworms. ( $3^{\text {rd }}$ edn), Chapman and Hall Press, London.

8. Muscolo A, Bovalo F, Gionfriddo F, Nardi S (1999) Earthworm humic matter produces auxin-like effects on Daucus carota cell growth and nitrate metabolism. Soil Biol Biochem 31(9): 1303-1311.

9. Quaggiotti S, Ruperti B, Pizzeghello D, Francioso O, Tugnoli V, et al. (2004) Effect of low molecular size humic substances on nitrate uptake and expression of genes involved in nitrate transport in maize (Zea mays L.). J Expt Bot 55(398): 803-813.

10. Tognetti C, Laos F, Mazzarino MJ, Hernandez MT (2005) Composting vs. vermicomposting: A comparison of end product quality. Compost Sci and Utilization 13(1): 6-13.

11. Tognetti C, Mazzarino MJ, Laos F (2008) Compost of municipal organic waste: Effects of different management practices on degradability and nutrient release capacity. Soil Biol Biochem 40(9): 2290-2296.

12. Mueller ND, Gerber JS, Johnston M, Ray DK, Ramankutty N, et al. (2012) Closing yield gaps through nutrient and water management. Nature 490: 254-257.

13. Arancon NQ, Edwards CA, Bierman P, Metzger JD, Lee S, et al. (2003) Effects of vermicomposts on growth and marketable fruits of fieldgrown tomatoes, peppers and strawberries. Pedobiologia 47(5-6): 731735.

14. Arancon, N, Edwards CA, Bierman P, Metzger JD, Lucht C (2005) Effects of vermicomposts produced from cattle manure, food waste and paper waste on the growth and yield of peppers in the field. Pedobiologia 49(4): 297-306.

15. Atiyeh RM, Subler S, Edwards CA, Bachman G, Metzger JD, et al. (2000) Effects of vermicompost and composts on plants growth in horticultural container media and soil. Pedobiologia 44(5): 579-590.

16. Atiyeh RM, Edwards CA, Subler S, Metzger JD (2001) Pig manure vermicompost as a component of a horticultural bedding plant medium: effects on physicochemical properties and plant growth. Bioresource Technol 78(1): 11-20.

17. Edwards CA, Arancon NQ, Vasko Bennet M, Keeney G (2010) Effects of aqueous extracts from vermicomposts on attacks by cucumber beetles (Acalymna vittatum) (Fabr.) on cucumbers and tobacco hornworm (Manduca sexta) (L.) on tomatoes. Pedobiologia 53(2): 141-148.

18. Llaven MAO, Jimenez JLG, Coro BIC, Rosales RR, Molina JM, et al. (2008) Fruit characteristics of bell pepper cultivated in sheep manure vermicompost substituted soil. J Plant Nutrition 31(9): 1585-1598. 
19. Hashemimajd K, Kalbasi M, Golchin A, Shariatmadari H (2004) Comparison of vermicompost and composts as potting media for growth of tomatoes. J Plant Nutrition 27(6): 1107-1123.

20. Adi AJ, Noor ZM (2009) Waste recycling: utilization of coffee grounds and kitchen waste in vermicomposting. Bioresource Technol 100(2): 1027-1030.

21. Jamaludin AA, Mahmod NZ (2010) Effects of vermicomposting duration to macronutrient elements and heavy metals concentrations in vermicompost. Sains Malaysiana 39(5): 711-715.

22. Orozco FH, Cegarra, J, Trujillo LM, Roig A (1996) Vermicomposting of coffee pulp using the earthworm Eisenia fetida: Effects on $\mathrm{C}$ and $\mathrm{N}$ contents and the availability of nutrients. Biol Fertil Soils 22: 162-166.

23. Premuzic Z, Bargiela M, Garcia A, Rendina A, Iorio A (1998) Calcium, iron, potassium, phosphorus and vitamin $\mathrm{C}$ content of organic and hydroponic tomatoes. Hort Science 33(2): 255-257.

24. Singh R, Sharma RR, Kumar S, Gupta RK, Patil RT (2008) Vermicompost substitution influences growth, physiological disorders, fruit yield and quality of strawberry (Fragaria $x$ ananassa Duch.) Bioresource Technol 99(17): 8507-8511.

25. Premuzic Z, Garate A, Bonilla I (2002) Production of lettuce under different fertilization treatments, yield and quality. Acta Hort 571(6): 65-72.

26. Mozafar A (1994) Plant vitamins: Agronomic, physiological, and nutritional aspects. CRC Press, Boca Raton, FL, USA, p. 412.

27. Muramoto J (1999) Comparison of nitrate content in leafy vegetables from organic and conventional farms in California. Center for Agroecology and Sustainable Food Systems, University of California, Santa Cruz.

28. Albuzio A, Ferrari G, Nardi S (1986) Effects of humic substances on nitrate uptake and assimilation of barley seedlings. Can J Soil Sci 66: 731-736.

29. Herman RJ (1979) Soil survey of Jackson County, Ill. Ill Ag Exp Stat Soil Report no. 106. Champaign-Urbana, IL, USA.

30. Smirnoff N (1996) The function and metabolism of AA in plants. Annals Bot 78: 661-669.
31. Marshner P (2012) Mineral nutrition of higher plants. ( $3^{\text {rd }}$ edn), Academic Press, Elsevier, San Diego, CA, USA, p. 672.

32. AOAC (2007) Official methods of analysis. $\left(18^{\text {th }}\right.$ edn), Association of Official Analytical chemists, Gaithersburg, MD, USA.

33. Hopkins WG, Hüner NPA (2003) Introduction to Plant Physiology, ( $3^{\text {rd }}$ edn), Wiley, New York, USA, p. 576.

34. Cruz C, Bio AFM, Dominguez Valdivia MD, Aparicio Tejo PM, Lamsfus C, et al. (2006) How does glutamine synthetase activity determine plant tolerance to ammonium? Planta 223(5): 1068-1080.

35. Tomati U, Galli E, Grapelli A, Dihena G (1990) Effects of earthworm casts on protein synthesis in radish (Raphanus sativum) and lettuce (lactuca sativa) seedlings. Biol Fertil Soils 9: 288-289.

36. Alderfasi AA, Moftah AE, Aljuaed AM (2010) Prospective study of using bio-organic farming system on growth, nitrate, oxalate and ascorbic acid contents in spinach. World Appl Sci J 9(1): 49-54.

37. Elias A, Santamaria P, Serio F (1998) Nitrogen nutrition, yield and quality of spinach. J Sci Food Agric 76(3): 341-346.

38. Nannipieri P, Eldor P (2009) The chemical and functional characterization of soil N and its biotic components. Soil Biol Biochem 41(12): $2357-$ 2369.

39. Theunissen J, Ndakidemi PA, Laubscher CP (2010) Potential of vermicompost produced from plant waste on the growth and nutrient status in vegetable production. Intl J Phys Sci 5(13): 1964-1973.

40. Canellas LP, Piccolo A, Dobbs LB, Spaccini R, Olivares FL, et al. (2010) Chemical composition and bioactivity properties of size-fractions separated from a vermicompost humic acid. Chemosphere 78(4): 457466.

41. Nardi S, Concheri G, Dell Agnola G (1996) Biological activity of humus. In: Piccolo A (Ed.), Humic substances in terrestrial ecosystems. Elsevier Science, Amsterdam, The Netherlands, pp. 361-407.

42. Krishnamoorthy RV, Vajrabhiah SN (1986) Biological activity of earthworm casts: an assessment of plant growth promoter levels in casts. Proc Indian Acad Sci (Anim Sci) 95(3): 341-351. 